\title{
MOSTRA DE MATEMÁTICA: DEMONSTRAÇÕES, EXPERIMENTAÇÕES E CONHECIMENTOS
}

\author{
MATHEMATICS DISPLAY: DEMONSTRATIONS, EXPERIMENTS AND KNOWLEDGE
}

\author{
Cláudia Landin Negreiros, Maria Margareth Krause, Luciana B. Machado, Maria Elizabete Rambo \\ Kochhahn
}

Universidade do Estado de Mato Grosso (Unemat) - câmpus Barra do Bugres

E-mail: clnegreiros@unemat.br, margarethkrause@unemat.br, lucianabm@unemat.br, beterambo@gmail.com

\section{Resumo}

Este artigo traz considerações sobre uma mostra itinerante e interativa ocorrida em 2014, tendo como loci cinco escolas públicas de Mato Grosso. Implementada por docentes e acadêmicos da Universidade do Estado de Mato Grosso (Unemat) câmpus de Barra do Bugres, a Mostra de Matemática teve como objetivos: divulgar e socializar experiências de Matemática e Ciências aos alunos dessas instituições. Especificamente, neste artigo, apresentamos a etapa de uma escola no município de Barra do Bugres. E por meio de relatos produzidos pelas comunidades acadêmica e escolar, analisamos os sentidos manifestados nesses textos, os quais nos levam a discutir aspectos da relação universidade e escola, a qual é construída também por intermédio de projetos de pesquisa e extensãosumão.

Palavras-chave: políticas públicas educacionais. matemática. ciências. educação básica. mostra de matemática.

\section{Abstract}

This article looks at an interactive, travelling display that took place in 2014, visiting five public schools in Mato Grosso. A creation of teachers and academics from the University of the State of Mato Grosso (Universidade do Estado de Mato Grosso; UNEMAT), Barra do Bugres Campus, A Mathematics Display was designed to publicize and socialize Mathematics and Science experiments among students of the target institutions. Specifically, in this article we show the experience of one school in the municipality of Barra do Burges. Drawing on reports produced by the academic and school communities, we analyze the recorded feelings. This brings us to discuss aspects of the university-school relationship, which is also a result of research and outreach projects.

Palavras-chave: public edication policies. mathematics. science. basic education. mathematics display. 


\section{INTRODUÇÃO}

O que trazemos neste artigo são considerações advindas da experiência didática intitulada Mostra de Matemática, realizada por docentes e acadêmicos bolsistas dos Projetos Observatório da Educação com Foco em Matemática e Iniciação às Ciências (OBEDUC) ${ }^{1}$ e Novos Talentos ${ }^{2}$.

Com financiamentos advindos da Coordenação de Aperfeiçoamento de Pessoal de Nível Superior (Capes), ambos Projetos são implementados pela Universidade do Estado de Mato Grosso (Unemat) - câmpus Barra do Bugres, vinculados ao curso de Licenciatura em Matemática. Nesses programas, são realizadas intervenções junto aos professores e alunos de escolas públicas de municípios localizados no interior deste estado.

Tendo como foco a Educação Básica, a agência financiadora requer das Instituições de Ensino Superior (IES), que implementam tais Projetos, que as mesmas alcancem os principais objetivos para os quais foram criados, respectivamente: (1) OBEDUC - alterar os Índices de Desenvolvimento da Educação Básica (IDEB) das escolas brasileiras; (2) Novos Talentos apoiar propostas para realização de atividades extracurriculares para professores e alunos da Educação Básica, visando à disseminação do conhecimento científico, ao aprimoramento e à atualização do público-alvo e à melhoria do ensino de Ciências e Matemática nas escolas públicas do país.

Iniciamos nossas considerações com a apresentação, em linhas gerais, desses dois Projetos. A seguir, discorremos sobre o evento itinerante e interativo Mostra de Matemática, desde a sua gênese à sua implementação, além dos objetivos gerais e específicos, da configuração e da metodologia. Na sequência, o foco deste estudo, ou seja, a etapa do evento realizada em uma escola do município de Barra do Bugres. Neste tópico, analisamos os sentidos manifestados nos relatos dos participantes (da universidade e da escola) e também nos

1 Edital no 038/2010/CAPES/INEP.

2 Edital 055/2012 - CAPES, Projeto Novos Talentos - Descobrindo Talentos na Educação Básica de Escolas de Mato Grosso. 
relatórios científicos dos acadêmicos bolsistas (universidade). E, por fim, nossas considerações finais e agradecimentos a todos que, de alguma maneira, trabalham com o intuito de cooperação para enfrentar as demandas de conhecimentos científico e tecnológico que essa modalidade de educação requer.

\section{POLÍTICAS PÚBLICAS EDUCACIONAIS: OS PROJETOS OBEDUC E NOVOS TALENTOS NA UNEMAT}

O OBEDUC se consolidou como uma das ações empreendidas por três Instituições de Ensino Superior (IES), cujo objetivo era fortalecer a pesquisa e a pós-graduação nas instituições envolvidas, bem como nas escolas de Educação Básica parceiras. Este projeto se inscreve, então, no rol das políticas públicas educacionais que visam a fomentar programas de pesquisa e extensão em diferentes áreas do conhecimento, com o intuito de fortalecer a relação entre universidade e escola. E é por meio dessas ações que se buscam perspectivas para acelerar o desenvolvimento desses programas, incorporando conhecimento a partir da realidade dos Estados onde se localizam tais instituições.

Assim é que as Ciências e a Matemática foram as áreas convocadas para atender ao Edital no 038/2010/CAPES/INEP, o qual fomenta "[...] estudos e pesquisas em educação, que utilizem a infraestrutura disponível das Instituições de Educação Superior - IES e as bases de dados existentes no INEP" (BRASIL, 2008, s/p). Essas áreas estão relacionadas aos três eixos que configuram o Projeto, quais sejam: formação inicial e continuada de professores, Avaliação em Larga Escala (ALE) e Ciência, Tecnologia, Sociedade e Ambiente (CTSA).

Envolvendo pesquisadores de três IES, a Universidade do Estado de Mato Grosso (Unemat) câmpus Barra do Bugres, a Universidade Federal de Mato Grosso (UFMT) - câmpus Cuiabá, e a Universidade Estadual Paulista "Júlio de Mesquita Filho" (Unesp) - câmpus Ilha Solteira, inseridos em cursos de graduação e pós-graduação, há também a participação de professores de escolas de Educação Básica, parceiras nas atividades de investigação, os quais 
são também convidados a colaborar neste projeto, de alguma maneira.

Mas como pesquisadoras, queríamos que os alunos dessas escolas fossem também parceiros. E uma nova oportunidade surgiu, em dezembro de 2012, quando atendemos ao Edital 055/2012 - Capes, aprovando o Projeto Novos Talentos, denominado Descobrindo Talentos na Educação Básica de Escolas de Mato Grosso. Uma possibilidade de dinamizar as lideranças e alunos dessas escolas, com o intuito de "[...] apoiar propostas para realização de atividades extracurriculares para professores e alunos da Educação Básica, tais como cursos, oficinas ou equivalentes, que ocorram no período de férias [...]" (BRASIL, 2010, s/p).

Especificamente, os objetivos desses dois projetos são: (1) OBEDUC - diagnosticar as dificuldades em matemática e ciências de alunos da Educação Básica das escolas das redes públicas de ensino, bem como coordenar as propostas e intervenções dos participantes por meio de recorrentes apresentações e discussões das mesmas, em diferentes fóruns (locais e gerais), visando ao enfrentamento da problemática encontrada nos loci selecionados para atuação; (2) Novos Talentos - oportunizar aos estudantes de diferenciado desempenho acadêmico e seus professores possibilidades que cultivem a inovação, a descoberta, a curiosidade, o fazer ciência e um uso avançado das tecnologias de informação e comunicação, criando espaços para a chamada geração $Y$ desenvolver novas competências básicas para a sua sobrevivência, pensar e construir projetos próprios e altamente críticos em relação aos que existem na sociedade atual.

Tendo como cenário escolas da rede pública de ensino dos municípios mato-grossenses de Barra do Bugres, Tangará da Serra, Nova Olímpia, Nortelândia, Cáceres, Rondonópolis, Sinop e Sorriso. Ambos projetos são implementados pela Unemat, uma universidade inserida no interior do estado, na região da Amazônia Legal, com sede no município de Cáceres e uma estrutura multicâmpus composta atualmente por 13 câmpus universitários e 14 núcleos pedagógicos. 
Uma das ações empreendidas por esses dois projetos é a realização da Mostra de Matemática, que comentamos mais detalhadamente no item subsequente.

\section{A MOSTRA DE MATEMÁTICA}

Com os objetivos de divulgar e socializar experiências, pesquisas e atividades de Matemática e Ciências, esta Mostra ocorreu no 2ํ semestre de 2014 em escolas públicas dos municípios de Barra do Bugres, Tangará da Serra, Nova Olímpia e Nortelândia. No quadro a seguir, as escolas atendidas e a data do evento.

Quadro 1. Escolas atendidas.

\begin{tabular}{|c|c|c|}
\hline Escolas atendidas & Município & Data \\
\hline E.E. Prof. a Idalina de Farias & Nortelândia & $10 / 10 / 2014$ \\
\hline E.E. João Monteiro Sobrinho & Nova Olímpia & $18 / 10 / 2014$ \\
\hline E.E. 07 de Setembro & Barra do Bugres - Distrito de Assari & $24 / 10 / 2014$ \\
\hline E.E. Emanuel Pinheiro & Tangará da Serra & $30 / 10 / 2014$ \\
\hline E.E.E. Assembléia de Deus & Barra do Bugres & $28 / 11 / 2014$ \\
\hline
\end{tabular}

Fonte: dados da investigação, 2014.

Assim é que ao idealizarmos esta Mostra, pensamos estar em consonância com os propósitos da Organização das Nações Unidas para a Educação, a Ciência e a Cultura (UNESCO). Ou seja, para celebrar a virada do milênio, esta instituição fixou o ano 2000 como o Ano Internacional da Matemática, em virtude dos desafios que esta ciência iria enfrentar neste século e a capacidade da Matemática como ferramenta de ajuda para resolvê-los.

E em comemoração a esse acontecimento, foi montada na França a Mostra de Matemática Math 2000, no museu Cité des Sciences et de I'Industrie / La Villette, com uma abordagem empírica e lúdica, cujas experiências realizadas nesse evento puderam ser manuseadas por alunos, por exemplo: em forma de quebra-cabeças, brinquedos e até mesmo um jogo da velha espacial. Pela manipulação dos experimentos, a mostra pôde colocar o visitante em contato com a Matemática, tornando-a uma ciência acessível e compreensível, saindo 
unicamente do plano abstrato ${ }^{3}$.

Após as discussões iniciais na Unemat, a mostra foi se delineando, e a partir dos encontros realizados no 1 o semestre de 2014 , alguns eixos que comporiam os trabalhos dessa experiência didática já eram sinalizados. Nas reuniões seguintes (agosto/setembro de 2014), estabeleceram-se, por fim, os seis eixos temáticos que a moldariam:

- Jogos e Materiais Lúdicos

- Uso das TIC (computador e celular)

- $\quad$ llusões de ótica e curiosidades

- $\quad$ Geometria: Possibilidades com espelhos

- $\quad$ Experimentos químicos

- $\quad$ Experimentos físicos ${ }^{4}$

No quadro seguinte, dispomos os objetivos de cada eixo temático.

Quadro 2. Eixos Temáticos da Mostra e objetivos gerais.

\begin{tabular}{|l|l|}
\hline \multicolumn{1}{|c|}{ Eixos Temáticos } & \multicolumn{1}{|c|}{ Objetivos Gerais } \\
\hline 1. Jogos e Materiais Lúdicos & $\begin{array}{l}\text { Desenvolver o raciocínio lógico das crianças e suas } \\
\text { habilidades, levando-as a conceberem a Matemática } \\
\text { como uma disciplina prazerosa, além de proporcionar a } \\
\text { criação de vínculos positivos na relação professor-aluno } \\
\text { e aluno-aluno. }\end{array}$ \\
\hline 2. Uso das TIC (computador e celular) & $\begin{array}{l}\text { Mostrar aos alunos formas diferenciadas de uso das TIC } \\
\text { na escola e também na vida diária. }\end{array}$ \\
\hline 3. Ilusões de ótica e curiosidades & $\begin{array}{l}\text { Explorar o sentido visual dos alunos e apresentar } \\
\text { algumas curiosidades explicadas pela Física. }\end{array}$ \\
\hline 4. Geometria: Possibilidades com espelhos & Identificar nas construções com materiais manipuláveis \\
as propriedades dos polígonos e de alguns poliedros,
\end{tabular}

3 Disponível em: <http://web3.ufes.br/petmat/node/45>. Acesso em: 15 fev. 2015.

4 Esclarecemos que os dois últimos eixos, Experimentos químicos e Experimentos físicos, compõem a Mostra em virtude de ambos os Projetos (OBEDUC e Novos Talentos) também contemplarem o ensino de Ciências. 


\begin{tabular}{|l|l|}
\hline 5. Experimentos químicos & ângulos, simetrias e pavimentação. \\
\hline 6. Experimentos físicos & $\begin{array}{l}\text { Mostrar aos alunos dos anos iniciais e finais do Ensino } \\
\text { Fundamental, através de experimentos usando-se } \\
\text { alimentos in natura e industrializados, que a Química } \\
\text { encontra-se presente no cotidiano. }\end{array}$ \\
\hline Despertar os alunos para a relação existente entre a \\
Matemática, a Física e o cotidiano.
\end{tabular}

Fonte: Dados da investigação, 2014.

Para dar cumprimento aos objetivos traçados ${ }^{5}$, realizou-se uma metodologia de acordo com o planejamento feito por toda a equipe organizadora (docentes e acadêmicos bolsistas da Unemat). Ou seja, conforme a fase de ensino (do 4 을 ao 9 을 anos do Ensino Fundamental) mudava-se a linguagem matemática e também a científica para que houvesse melhor entendimento por parte dos alunos.

Não podemos deixar de mencionar que em todas as escolas participantes da Mostra sempre obtivemos o apoio da gestão, que esteve atenta na organização dos espaços necessários para que o evento ocorresse. Além disso, a logística foi planejada com o intuito de que todos os alunos tivessem acesso aos seis eixos. Assim, era feito um rodízio no qual cada turma ficava aproximadamente 20 minutos em determinado eixo, participando interativamente com os docentes e bolsistas. Depois desse período, ocorria a troca, ou seja, essa turma saía e uma nova entrava até que todas fossem contempladas.

Essa dinâmica ocorreu em todas as unidades escolares, mas como antecipado, neste estudo comentamos mais detalhadamente a etapa realizada em uma das escolas do município de Barra do Bugres.

\section{A MOSTRA DE MATEMÁTICA NA ESCOLA ESTADUAL EVANGÉLICA ASSEMBLÉIA DE DEUS}

Barra do Bugres, município do interior do Estado de Mato Grosso, situa-se a $170 \mathrm{Km} \mathrm{da}$

5 Trazemos os objetivos específicos de cada eixo ao final deste estudo, nos Anexos. 
capital, Cuiabá, com pouco mais de 30 mil habitantes, e que se constitui como um espaço de diversidades étnico-culturais: indígenas, quilombolas, assentados, migrantes. Uma cidade atravessada pela diversidade.

É nesse contexto onde está inserida a Escola Estadual Evangélica Assembléia de Deus, uma instituição instalada em um prédio sob o regime de comodato, localizada na periferia da cidade, e que oferece apenas os anos iniciais do Ensino Fundamental. Dessa forma, os alunos, ao finalizarem o 2 - Ciclo, dirigem-se para outras unidades escolares circunvizinhas a fim de prosseguirem seus estudos.

Em 2014, o número de alunos matriculados nessa instituição era de 616, cuja estrutura física é constituída de 14 salas de aula; uma sala para os professores; uma sala para Articulação da Aprendizagem ${ }^{6}$; uma sala para a secretaria; um banheiro para professores e funcionários; banheiros para alunos, quatro femininos e quatro masculinos; cozinha; área de serviço; depósito; refeitório; uma cantina, alugada por terceiros; biblioteca; laboratório de informática; um pequeno auditório, com som, TV, DVD, datashow; uma quadra sem piso e sem cobertura, apenas areia; uma sala de recursos multifuncionais destinada ao psicopedagogo para atender os alunos com necessidades especiais, especificamente aqueles com deficiência intelectual. Na sequência, na figura1, o pátio interno da escola.

6 Articulação da Aprendizagem é uma proposta inovadora nas escolas estaduais do estado de Mato Grosso cujo objetivo é atender o aluno com necessidade de aprendizagem (no contraturno), utilizando estratégias pedagógicas complementares, proporcionando vivências formativas, cidadãs, e integradas às atividades desenvolvidas pelo professor regente. 
Figura 1. Pátio interno da EE Evangélica Assembléia de Deus.

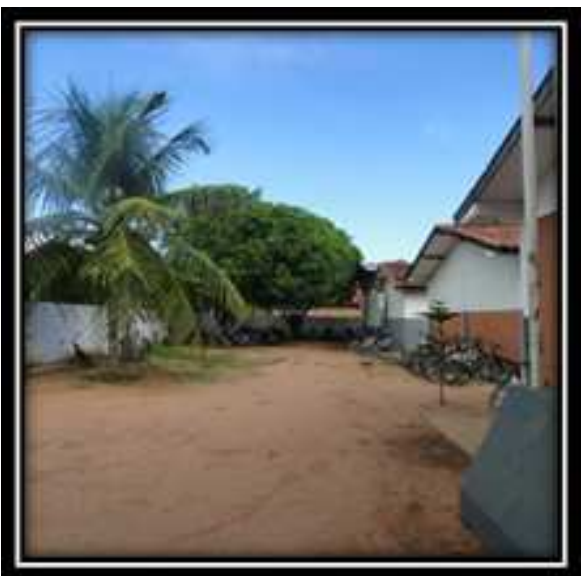

Fonte: dados da investigação, 2014

Desses alunos ${ }^{7}, 355$ participaram da Mostra de Matemática, ocorrida em uma sexta-feira, no período matutino, com a participação dos professores, coordenadores e gestão. As figuras 2, $3,4,5,6$ e 7 a seguir mostram este evento ${ }^{8}$.

Figura 2. Jogos e Materiais Lúdicos.

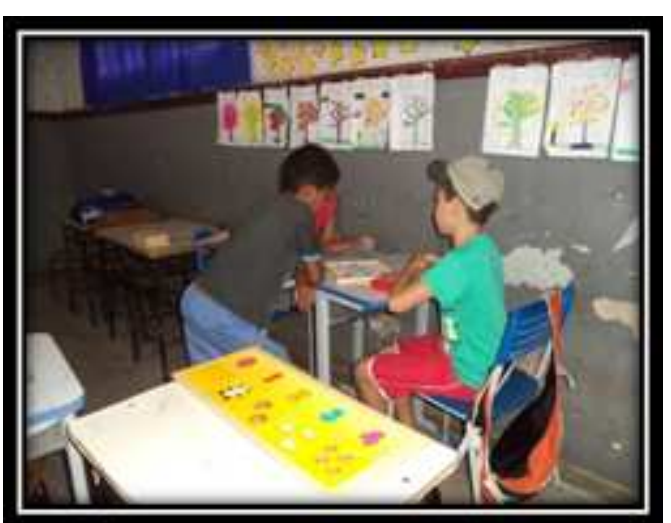

Fonte: Dados da investigação, 2014.

7 Ressaltamos que todos os registros em imagens dos alunos foram autorizados pela direção escolar no momento em que realizamos o convite para a participação na Mostra de Matemática; nas demais escolas participantes também obtivemos autorização.

8 Disponibilizamos mais imagens desta Mostra no final deste artigo, em seus Anexos. 
Figura 3. Uso das TIC (computador e celular).

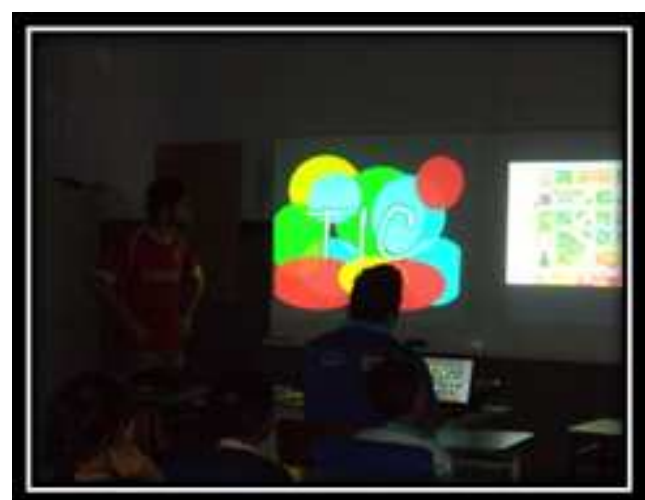

Fonte: Dados da investigação, 2014.

Figura 4. llusões de ótica e curiosidades.

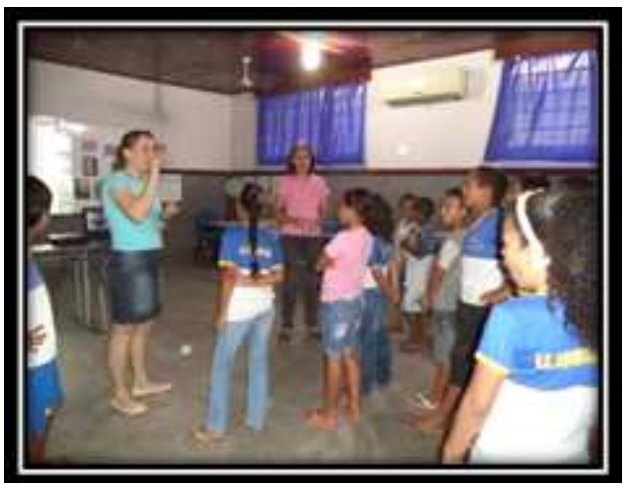

Fonte: Dados da investigação, 2014.

Figura 5. Simetrias.

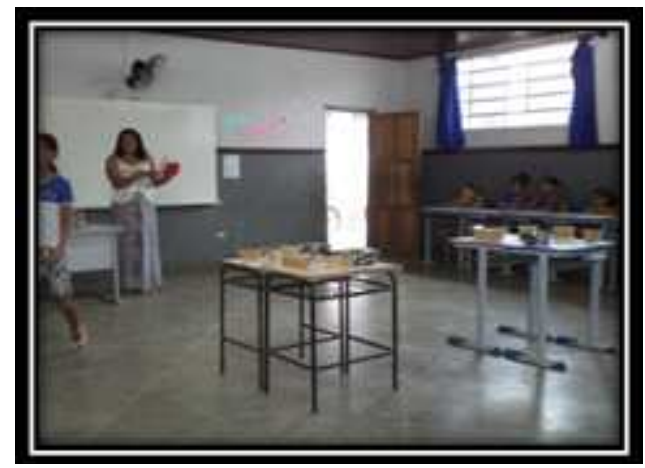

Fonte: Dados da investigação, 2014. 
Figura 6. Experimentos químicos.

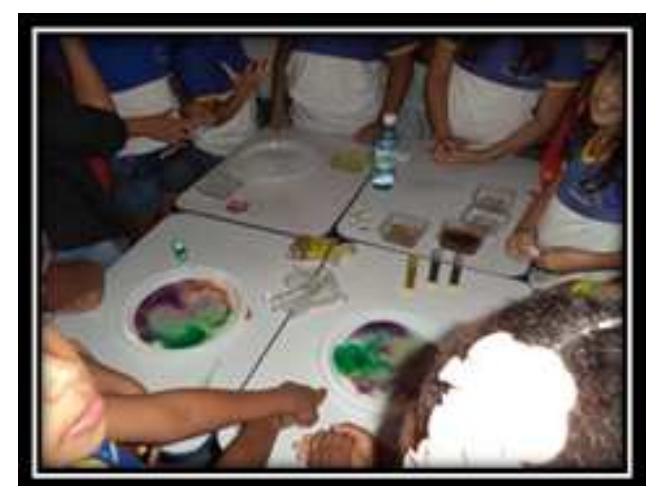

Fonte: Dados da investigação, 2014.

Figura 7. Experimentos físicos.

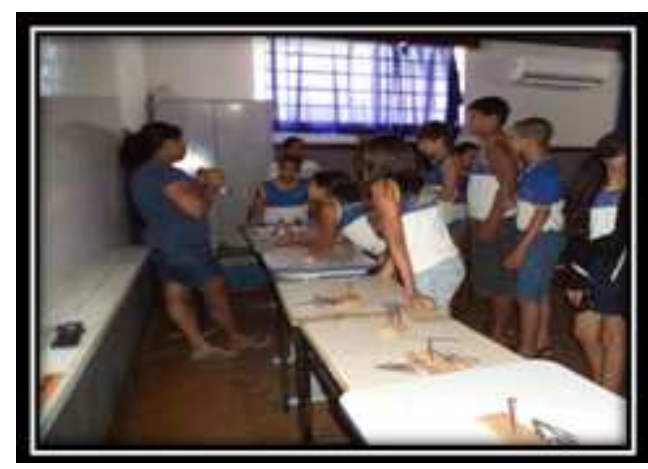

Fonte: Dados da investigação, 2014.

Por essas imagens, pode-se perceber a participação dos alunos, e também o envolvimento dos professores que os acompanhavam durante o percurso. No item subsequente, analisamos os sentidos manifestados nos relatos dos participantes da Mostra nesta escola.

\section{OUVIR A VOZ, CONCEDER A PALAVRA: ANALISANDO OS RELATOS}

Apresentamos, na sequência, os relatos produzidos pelos dois segmentos envolvidos na Mostra: a comunidade acadêmica (relatórios científicos) e a escolar (relatos orais transcritos), bem como as nossas considerações sobre os mesmos.

\subsection{Relatos da comunidade acadêmica}

1. Jogos e materiais lúdicos 
A mostra nesta escola foi muito tumultuada, com a participação de 10 turmas (do $1^{\circ}$ ao $6^{\circ} \mathrm{Ano}$ do EF) apenas no período matutino. A participação de alunos desta fase inicial de ensino foi muito importante em nossa visão. Os diferentes tipos de jogos que tínhamos na sala chamavam muito atenção deles. Isso fez com que refletíssemos sobre o ensino diferenciado iniciado nesta fase. As crianças do $1^{\circ}$ ao $3^{\circ}$ Ano tiveram um raciocínio em relação à Torre de Hanói que nenhuma turma anterior teve. Elas queriam tentar passar todos os círculos rapidamente. Verificamos que o raciocínio dessas crianças nessa atividade foi muito proveitoso. Mas apesar do tempo ser muito pouco para cada turma, a Mostra se tornou um momento inesquecível tanto para alunos como para os funcionários da escola.

2. Uso das TIC (computador e celular)

Nosso tema da Mostra era voltado de acordo com a idade dos alunos. Primeiro fizemos uma abordagem sobre o significado de TIC e como temos contato com essas tecnologias em nossas vidas. Na sequência, apresentamos alguns jogos e materiais que podiam ser usados na escola ou na vida diária. Até o 5o Ano mostramos alguns jogos cujos temas eram: frações, dominó, etc. Após isso, realizamos competições entre os alunos. Percebemos que os alunos desta escola foram muito participativos, colaborando uns com os outros, mesmo nos momentos de competição. Quanto à participação dos professores, percebemos que eles gostaram muito da ideia de uma aula diferenciada.

3. Ilusões de ótica e curiosidades

Nesta escola, contamos com o total apoio da equipe escolar que se mobilizou para a realização do evento. Acredito que conseguimos alcançar o objetivo da nossa atividade, que era de explorar o sentido visual dos alunos e apresentar algumas curiosidades explicadas pela Física. Percebemos que os alunos menores (Ensino Fundamental I) estavam mais eufóricos e encantados com o que estava sendo apresentado a eles. Isso faz com que nós tenhamos muito mais entusiasmo na realização de eventos como estes, pois acreditamos estar contribuindo para o melhoramento na qualidade da Educação.

\section{Simetrias}

O trabalho com a Geometria foi de suma importância nesta escola, pois ofereceu possibilidades para alunos e professores agregarem conhecimento através das práticas e construções com materiais manipuláveis nos conteúdos de: polígonos, poliedros, ângulos, simetrias, pavimentação. No desenvolvimento das atividades com espelhos, percebi que despertou os alunos para o interesse dos conteúdos específicos ministrados. Também observei que a Mostra teve seu ponto máximo em demonstrar a Matemática sem se referir a cálculos matemáticos, que é o que se espera dos novos licenciados em Matemática, pois dá significação aos fenômenos para que os alunos possam aprender Matemática. A importância que se tem numa Mostra de experiências e experimentos como esta, faz com que os alunos da Educação Básica compreendam, indiretamente, o significado da Matemática na sua vida.

5. Experimentos químicos

Nesta escola, a proposta foi que os alunos compreendessem a maneira que as reações ácidobase ocorrem, além da importância do consumo de vitamina $C$, e também de que maneira identificar os teores da mesma em produtos alimentícios. Ademais, esperou-se que os estudantes entendessem o papel fundamental da água no cotidiano, suas características físicoquímicas e qual sua importância na indústria. Para isso, houve exposições teóricas e atividades práticas sobre o tema, para que os alunos assimilassem o conteúdo exposto. 


\section{Experimentos físicos}

A experiência na EE Evangélica Assembléia de Deus foi uma das melhores de todas da Mostra, porque foi a escola em que os alunos mais participaram. Eles foram bem dinâmicos e participativos. A nossa oficina tinha como tema "Física" e trazia alguns experimentos sobre centro de gravidade, equilíbrio e energia. Fazíamos os experimentos e explicávamos os porquês dos resultados. Logo em seguida, nós os desafiávamos com alguns problemas relacionados aos experimentos explicados. Nesta escola, muitos alunos conseguiram desvendar tais problemas, e, com isso, eles nos desafiaram. Coisa que nós não imaginávamos que poderia acontecer. Além de aprender, eles estavam se divertindo. Fiquei sabendo depois que os alunos "super adoraram" a mostra, e que um deles chegou todo feliz em casa porque conseguiu e gostou de aprender Física através da nossa intervenção.

Apesar das críticas feitas pelos acadêmicos, quanto à dinâmica da Mostra (A mostra nesta escola foi muito tumultuada...), esses manifestaram um sentido de satisfação por desenvolverem atividades com crianças, diferentemente do que ocorreu em outras unidades escolares (As crianças do $1^{\circ}$ ao $3^{\circ}$ Ano tiveram um raciocínio em relação à Torre de Hanói que nenhuma turma anterior teve...). Ao narrarem essa experiência, os acadêmicos relatam também o quanto a mesma foi importante para a comunidade escolar (... a Mostra se tornou um momento inesquecível tanto para alunos como para os funcionários da escola).

Mas há também um sentido de reconhecimento pelo compromisso desta comunidade escolar na realização da Mostra, o qual é manifestado pelos acadêmicos (Nesta escola, contamos com o total apoio da equipe escolar que se mobilizou para a realização do evento). Nota-se também o encantamento dos alunos durante a participação da oficina (Percebemos que os alunos menores - Ensino Fundamental I - estavam mais eufóricos e encantados com o que estava sendo apresentado a eles). Ao final, os acadêmicos desta oficina sinalizam a pertinência da Mostra no campo da Educação, desta maneira: "Isso faz com que nós tenhamos muito mais entusiasmo na realização de eventos como estes, pois acreditamos estar contribuindo para o melhoramento na qualidade da Educação."

Ao ensinar simetria, a acadêmica ressalta o interesse que esse conteúdo despertou nos alunos (No desenvolvimento das atividades com espelhos, percebi que despertou os alunos para o interesse dos conteúdos específicos ministrados). Para ela, foi na realização desta 
Mostra que pode perceber o quanto a Matemática, ensinada por meio de experiências como esta, pode fazer sentido para os alunos da Educação Básica ( $A$ importância que se tem numa Mostra de experiências e experimentos como esta, faz com que os alunos da Educação Básica compreendam, indiretamente, o significado da Matemática na sua vida).

Os acadêmicos tiveram um sentimento de desafio ao realizar as atividades de Física durante a Mostra ocorrida nesta escola. Assim: “... nós os desafiávamos com alguns problemas relacionados aos experimentos explicados. Nesta escola, muitos alunos conseguiram desvendar tais problemas, e, com isso, eles nos desafiaram. Coisa que nós não imaginávamos que poderia acontecer." Um sentido que os levou a dizer que "A experiência na EE Evangélica Assembléia de Deus foi uma das melhores de todas da Mostra, porque foi a escola em que os alunos mais participaram. Eles foram bem dinâmicos e participativos." Um momento de interação experienciado por ambas as partes; de um lado, os acadêmicos, ainda em formação inicial; e de outro, os alunos da escola aprendendo, questionando, e desafiando aqueles que os instigavam ao conhecimento.

Pudemos observar, então, por meio desses relatos produzidos, que a Mostra de Matemática se tornou um espaço onde ocorreu também a formação (inicial) desses acadêmicos: uma formação inicial em serviço. Sabemos, pois, que, para além das discussões e debates na academia, participar do contexto escolar desde a graduação é também formação.

É o que pensa Nóvoa (2009, p. 07), ao dizer que "[...] é essencial reforçar dispositivos e práticas de formação de professores baseadas numa investigação que tenha como problemática a ação docente e o trabalho escolar." O que também remete ao que Tardif e Raymond (2000, p. 217) discorrem sobre o cotidiano escolar, isto é, "[...] saber como viver numa escola é tão importante quanto saber ensinar na sala de aula [...] a inserção numa carreira e o seu desenrolar exigem que os professores assimilem também saberes práticos específicos aos lugares de trabalho, com suas rotinas, valores, regras etc." 
Assim é que Programas de iniciação à docência, como o OBEDUC procuram "[...] promover a inserção dos estudantes no contexto das escolas públicas desde o início da sua formação acadêmica para que desenvolvam atividades didático-pedagógicas sob orientação de um docente da licenciatura e de um professor da escola." (BRASIL, 2008, s/p), e estão em consonância com o que preconizam as políticas públicas educacionais implementadas pelo governo federal, em especial aquelas que se destinam à formação inicial em serviço, e também em consonância ao recomendado por Nóvoa (2009, p. 16), ao falar de uma nova postura de formação inicial de professores, desta forma: “Não haverá nenhuma mudança significativa se a 'comunidade dos formadores de professores' e a 'comunidade dos professores' não se tornarem mais permeáveis e imbricadas."

Nessa mesma direção, Mizukami et al. (2002, p. 74) consideram que "[...] o desenvolvimento profissional deve ser redefinido como parte central do ensino, não podendo consistir em tarefas esporádicas e externas". Por esse motivo a formação inicial em serviço tem o intuito de capacitar os futuros professores para enfrentar os desafios da realidade escolar, e ao mesmo tempo elevar a qualidade dessa formação inicial, intencionando promover a integração entre Educação Básica e Superior.

\subsection{Relatos da comunidade escolar}

\section{Gestão}

A princípio, eu desconhecia o funcionamento da mostra, não sabia como era que funcionava. Sabíamos que não era para todas as turmas, mas acabou envolvendo todas as do período matutino, pois são crianças e não dava para ficarem de fora. Todos adoraram o evento, tanto os alunos quanto os professores que levaram seus alunos para as salas onde ocorriam as oficinas. Uma crítica que faço é que as atividades deveriam ser feitas de acordo com a idade das crianças, mas assim mesmo elas gostaram muito.

2. Coordenação Pedagógica

Os alunos gostaram muito de todas as oficinas. Uma sugestão que tenho é que, antecipadamente, nos fosse comunicado de como seria a dinâmica da mostra, pois poderíamos ter ajudado muito mais nos trabalhos. Mas, mesmo assim, do jeito que ocorreu, todos gostaram muito, os alunos adoraram.

3. Professor

A mostra foi um momento em que nossos alunos tiveram um contato com as demais 
disciplinas como Física e Química. Um dos pontos relevantes dessas oficinas foi o tempo que foi muito curto, pois meus alunos ficaram sem ir a duas salas. Gostaria que essas oficinas fossem feitas todos os anos em nossa escola, e que o tempo seja organizado para que nenhuma turma fique sem o contato dessas atividades.

4. Aluno (4o ano do Ensino Fundamental)

Tia, as escolas deveriam ter sempre atividades assim, nunca nem tinha usado um joguinho do computador que estudava Matemática, é tão legal. Porque nossas tias da sala não passam para nós sempre. Eu gostei muito das tias da sala de Química, muito boa a aula delas. E aqui na sua sala tem muito joguinho muito bom e eu aprendi muito Matemática.

Podemos perceber, pelos relatos da comunidade escolar, que a Mostra de Matemática, apesar das críticas quanto ao desconhecimento da dinâmica, à insuficiência de tempo para a visitação de todas as turmas de alunos, e outros fatores que ocorreram durante a apresentação das oficinas, teve um significado relevante para os participantes, tal como sinalizado pela gestão: "Todos adoraram o evento, tanto os alunos quanto os professores que levaram seus alunos para as salas onde ocorriam as oficinas."

Vemos, ainda, que a gestão indicou a importância de se adaptar as atividades desenvolvidas à idade dos alunos (Uma crítica que faço é que as atividades deveriam ser feitas de acordo com a idade das crianças, mas assim mesmo elas gostaram muito). Explicamos-lhe, posteriormente, que o público-alvo dos programas OBEDUC e Novos Talentos são os alunos do Ensino Fundamental II, mas que não deixaríamos as crianças do EF I desta escola sem participar da Mostra. Pensamos que isso seja algo a ser reelaborado nas próximas edições.

Já a coordenação pedagógica sugeriu que lhe fosse antecipada a dinâmica da Mostra (Uma sugestão que tenho é que, antecipadamente, nos fosse comunicado de como seria a dinâmica da Mostra, pois poderíamos ter ajudado muito mais nos trabalhos. Mas, mesmo assim, do jeito que ocorreu, todos gostaram muito, os alunos adoraram). Reconhecemos que isso pode ter sido uma falha da equipe organizadora em não comunicar previamente à gestão, à coordenação e até mesmo aos professores sobre como seriam desenvolvidas as oficinas. Sabemos, seguramente, que este é outro item a ser corrigido nas futuras intervenções. 
Uma das professoras do EF I assim se manifestou: Gostaria que essas oficinas fossem feitas todos os anos em nossa escola, e que o tempo seja organizado para que nenhuma turma fique sem o contato dessas atividades. Para ela, o tempo destinado para a visitação e interação em todas as oficinas foi insuficiente. Sentiu que a não participação de duas oficinas foi prejudicial aos seus alunos, ainda crianças, mas sinaliza a pertinência de eventos dessa natureza, sugerindo, inclusive, que os mesmos ocorram todos os anos na escola. Ela atribui, portanto, um sentido de importância e reconhecimento ao trabalho desenvolvido pela universidade.

Encerrando os relatos da comunidade escolar, um aluno do 4ㅇ Ano do EF, assim se manifestou: "Tia, as escolas deveriam ter sempre atividades assim, nunca nem tinha usado um joguinho do computador que estudava Matemática, é tão legal. Porque nossas tias da sala não passam para nós sempre." O relato desse aluno nos permite pensar sobre a importância de se levar às escolas de Educação Básica atividades de cunho científico e tecnológico de forma interativa intermediadas pela universidade.

Acreditamos, por fim, que a Mostra de Matemática realizada nessa escola foi um acontecimento que dá visibilidade às áreas de Matemática e Ciências, mostrando, dessa forma, que as atividades desenvolvidas promoveram descobertas, experimentações, curiosidade e conhecimento, levando os alunos a estabelecerem relações dessas disciplinas ao seu cotidiano. Uma aventura pela Matemática e pelas Ciências. 


\section{CONCLUSÕES}

Sabemos que o que está posto como desafio ao conhecimento dos alunos da Educação Básica é a importância da Matemática e das Ciências no mundo e a sua desmistificação. Por esse motivo é que projetos como o OBEDUC e os Novos Talentos realizam a intermediação entre a universidade e a escola, com o intuito de fortalecer o ensino dessas disciplinas nessas instituições escolares. E é aqui que a universidade assume um de seus papéis, ou seja, a formação inicial de professores, e um exemplo dessa formação foi a realização dessa Mostra de Matemática, implementada por estes dois Projetos.

Ademais, pensamos que nesse processo, a universidade deve reconhecer que o locus de formação por excelência desses acadêmicos em formação inicial é a escola, o que Ihes garantirá uma formação inicial em serviço.

Acreditamos também que, ao realizarmos essa Mostra, alcançamos objetivos específicos propostos antes: (1) Despertar o interesse dos alunos da Educação Básica pela Matemática e pelas Ciências, mostrando a aplicação dessas na vida diária; (2) Integrr novos conhecimentos e tecnologias de informação e comunicação nos processos de ensino e de aprendizagem.

Por fim, ressaltamos que, para nós, a realização de projetos como esses, e das ações implementadas pelos mesmos, como a Mostra de Matemática, aqui apresentada, nos enseja a crer na relevância da Educação Básica para a formação do cidadão, preparando-o para um mundo em constante transformação. 


\section{AGRADECIMENTOS}

Somos gratas aos acadêmicos bolsistas, aos docentes e demais organizadores da Mostra de Matemática pela disponibilidade e comprometimento em todas as etapas de elaboração deste evento.

Agradecemos também à execução dos Projetos Novos Talentos e Observatório da Educação com Foco em Matemática e Iniciação às Ciencias (OBEDUC) à CAPES, ao INEP, às IES (UNEMAT, UNESP e UFMT), às Escolas de Educação Básica parceiras, à Secretaria de Educação do Estado de Mato Grosso (SEDUC), e principalmente à comunidade escolar (gestores, professores e alunos).

\section{REFERÊNCIAS}

BRASIL. Ministério da Educação. Coordenação de Aperfeiçoamento de Pessoal de Nível Superior - CAPES. Observatório da Educação. Brasília: MEC/Inep, 2008. Disponível em: <http://www.capes.gov.br/educacao-basica/observatorio-da-educacao>. Acesso em $10 \mathrm{fev}$. 2015.

Novos Talentos. Brasília: MEC/Inep, 2010. Disponível em: <http://www.capes.gov.br/educacao-basica/novos-talentos>. Acesso em 10 fev. 2015. MIZUKAMI, M. et al. Escola e aprendizagem da docência: processos de investigação e formação. São Carlos: EdUFSCar, 2002.

NÓVOA, A. Professores: Imagens do futuro presente. Lisboa, EDUCA, 2009.

TARDIF, M.; RAYMOND, D. Saberes, tempo e aprendizagem do trabalho no magistério. In Educação \& Sociedade, ano XXI, n. 73, dez. 2000, pp. 209-244. 


\section{ANEXOS}

\section{Oficina "Geometria: possibilidades com espelhos"}

Objetivos específicos

- Esboçar figuras simétricas com formas geométricas ou não;

- Identificar eixos de simetria ou não em uma figura geométrica;

- Identificar propriedades de quadriláteros e triângulos pela comparação de lados e ângulos;

- Reconhecer ângulos como mudanças de direção ou giros;

- Identificar por meio de caleidoscópios sólidos geométricos ou pavimentação.

Figura 8. Possibilidades com espelhos.

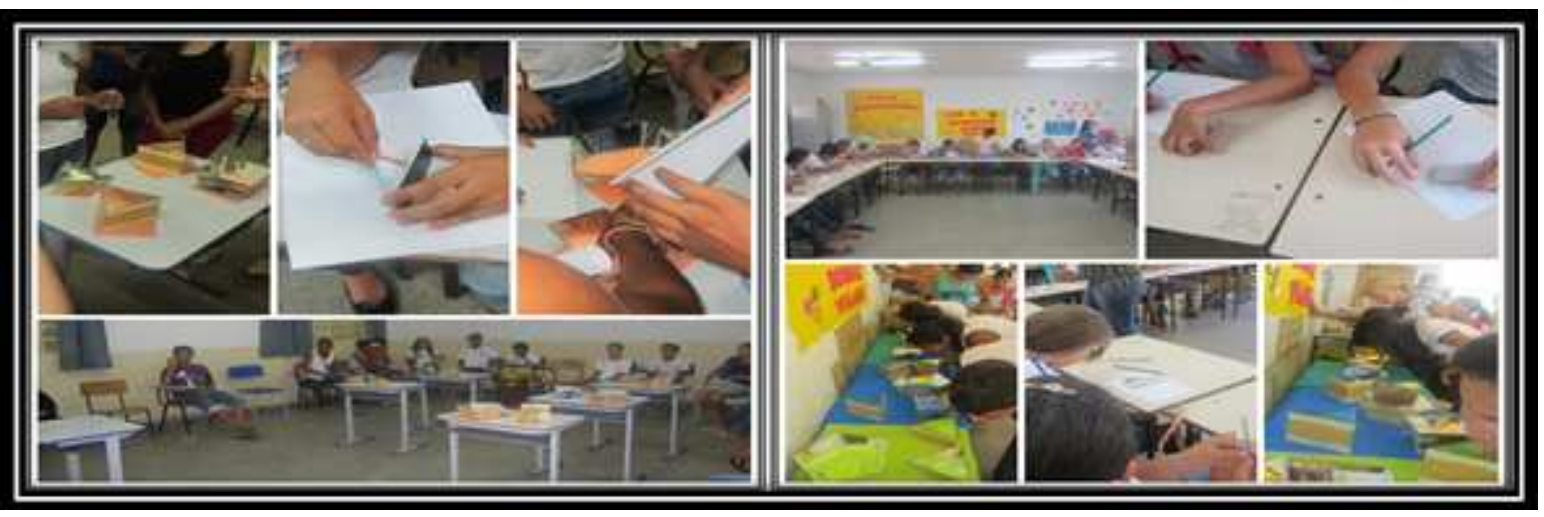

Fonte: Dados da investigação, 2014.

\section{Oficina "Jogos e materiais lúdicos"}

Objetivos específicos:

- Ampliar conhecimentos dos alunos sobre formas como a matemática pode ser trabalhada;

- Verificação dos conhecimentos relacionados ao raciocínio lógico e a cálculo mental;

- Manipular os materiais com intuito de aprendizagem de conceitos matemáticos. 
Figura 9. Jogos e materiais lúdicos.

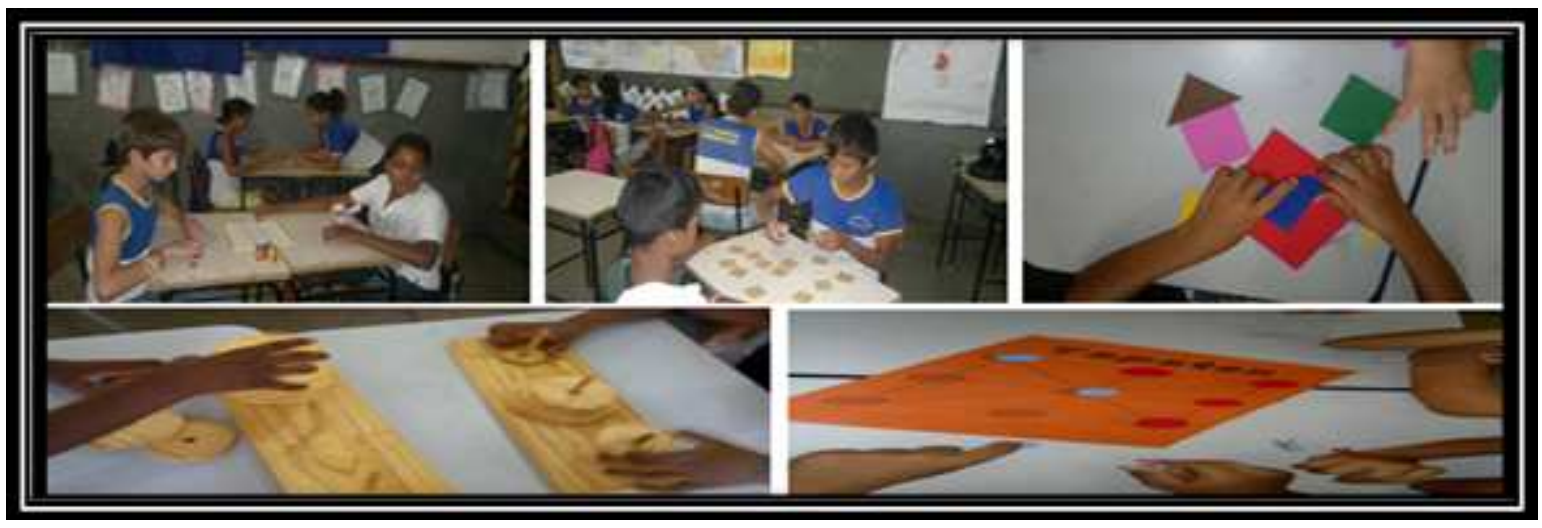

Fonte: Dados da investigação, 2014.

\section{Oficina "llusão de ótica e curiosidades"}

Objetivos específicos:

- Expor imagens que apresentam ilusões de ótica;

- Explicar o que é e como se forma a ilusão de ótica;

- Apresentar algumas curiosidades;

- Visualizar ilusões de ótica através da lente de celular;

- Utilizar computador e datashow na apresentação de vídeos e imagens.

Figura 10. Ilusão de ótica e curiosidades.

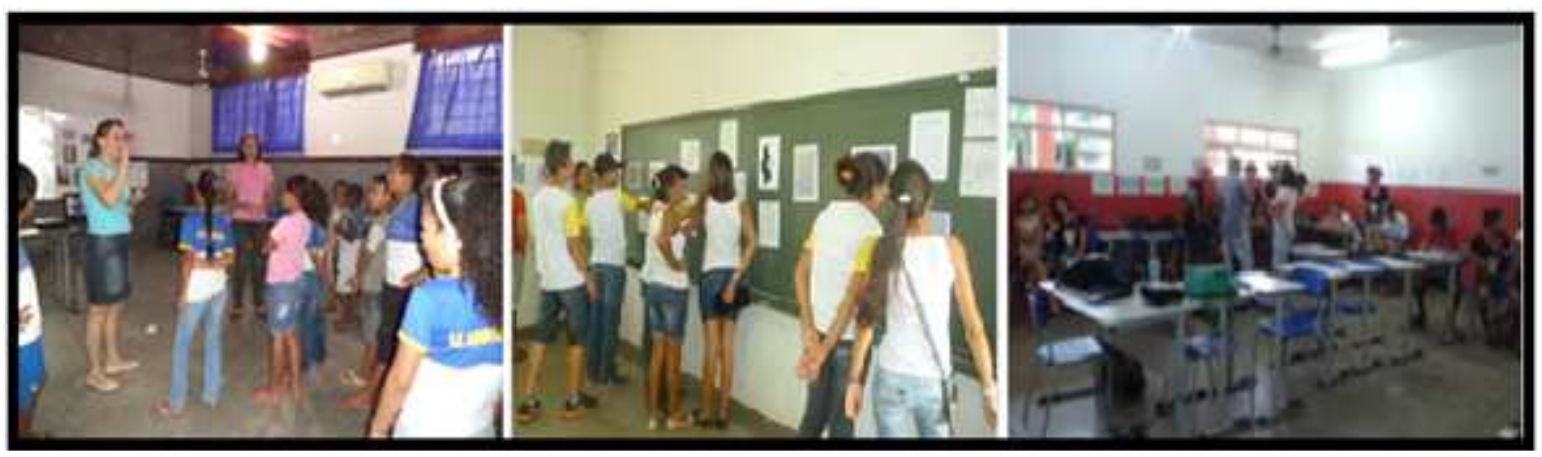

Fonte: Dados da investigação, 2014. 
Oficina de experimentos químicos “Dos frutos da terra à industrialização: possibilidades com a química e os avanços da ciência"

Objetivos específicos:

- Apresentar uma breve introdução da química no cotidiano, incluindo a realização de experimentos para exemplificar o que foi abordado;

- Abordar, simplificadamente, o conceito de substâncias ácidas e básicas, relacionando a importância para indústria de alimentos.

Figura 11. Experimentos químicos.

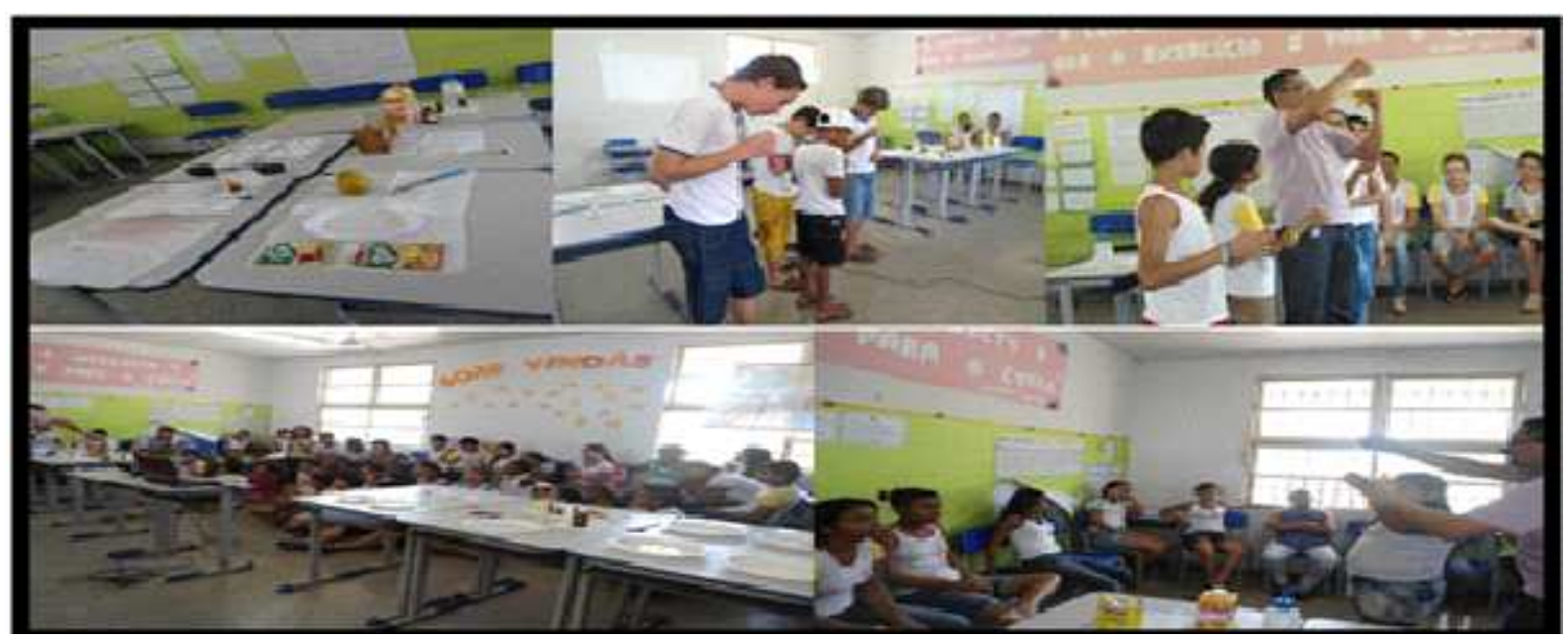

Fonte: Dados da investigação, 2014.

Oficina de experimentos físicos

Objetivos específicos:

- Mostrar como funciona e como é aplicada a primeira Lei de Newton;

- "Empilhar dez pregos na ponta de um", "equilibrar um garfo e uma colher na ponta de um palito de fósforo" trabalhando o centro de gravidade, facilitando o equilíbrio;

- Trabalhar ótica com a atividade "Água encantada". 
Figura 12. Experimentos físicos.

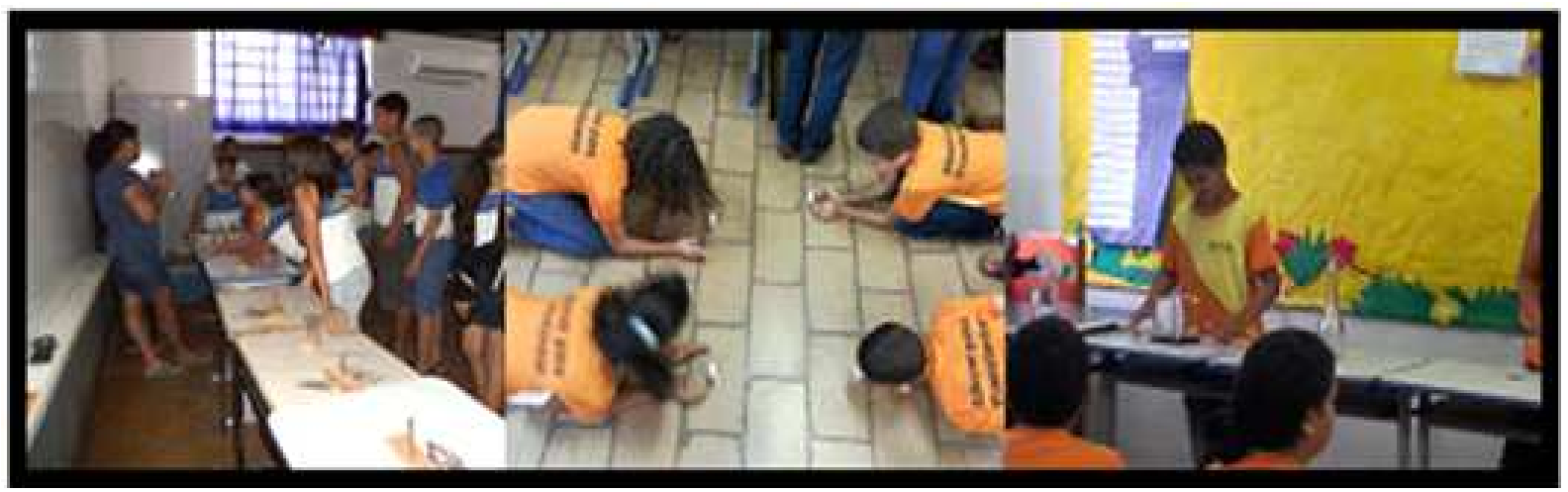

Fonte: Dados da investigação, 2014.

\section{Oficina "Uso das TIC (computador e celular)"}

Objetivos específicos:

- Apresentar as TIC e discutir como são utilizadas essas tecnologias em nosso cotidiano;

- Apresentar alguns jogos e materiais que podem ser utilizados em sala de aula;

- Realizar algumas competições entre os alunos utilizando as TIC como forma de motivar os alunos a aprender. 